\title{
Clinical efficacy of low molecular heparin on unexplained recurrent spontaneous abortion.
}

\author{
Guang-Li Xu, Xiao-Fang Hu, Yong-Mei Han, Ai-Wu Wei*
}

The Assisted Reproductive Center, the First Affiliated Hospital of Henan University of Traditional Chinese Medicine, Zhengzhou, Henan, PR China

\begin{abstract}
Objective: To study the clinical effect of low molecular heparin administered to patients with Unexplained Recurrent Spontaneous Abortion (URSA).

Methodology: A total of 120 URSA patients admitted to our hospital from October 2015 to September 2017 were taken as observation subjects. They were divided into two groups based on a random number table, that is, control group $(n=60)$ and observation group $(n=60)$. The patients in the control group were administered with progesterone and human chorionic gonadotropin, while the patients in the observation group were administered with low molecular heparin. The two groups were compared statistically in terms of pregnancy outcomes, incidence of complications in pregnancy, and incidence of adverse drug reactions.

Results: For the pregnancy outcomes, the pregnancy success rate of patients in the observation group is higher than that of the patients in the control group at $90.00 \%$ and $68.33 \%$, respectively, indicating a significant difference $(\mathbf{P}<\mathbf{0 . 0 5})$. For the incidence of complications in pregnancy, the results of the patients in the observation group are lower than those of the patients in the control group at $90.00 \%$ and $68.33 \%$, respectively, indicating a significant difference $(P<0.05)$. In the incidence of adverse drug reactions, the results of the comparison between the patients in the observation group and those in the control group are at $20.00 \%$ and $23.33 \%$, respectively, and no significant difference was observed (P>0.05).

Conclusion: Low molecular heparin administered to the URSA patients manifests a strong clinical effect. This treatment not only improves the pregnancy success rate but also reduces the incidence of complications. Furthermore, low molecular heparin is characterized by safety and reliability, and has potential for application in clinical studies.
\end{abstract}

Keywords: Unexplained recurrent spontaneous abortion, Low molecular heparin, Pregnancy outcomes, Pregnancy complications.

Accepted on November 29, 2017

\section{Introduction}

Unexplained Recurrent Spontaneous Abortion (URSA) refers to three or more consecutive spontaneous abortions that have occurred to a pregnant woman with the same sex partner, and without influences of chromosomal, immune, or endocrine dysfunction and genital tract infections [1,2]. As the cause is unknown, the pathogenesis of this condition remains unclear. No uniform treatment standard exists, and the clinical effect is unsatisfactory [3]. In recent years, continuous clinical studies have shown that the thrombus exists in the placental villus, umbilical blood vessels, and decidua basalis of some URSA patients [4]. Characterized by anti-thrombosis and anticoagulant effects, low molecular heparin can protect vascular endothelial cells, reduce blood viscosity, and enhance the microcirculation of the placenta to facilitate embryonic and fetal growth and development, thereby improving pregnancy outcomes [5]. To further explore the therapeutic effect of low molecular heparin, a total of 120 URSA patients admitted to our hospital from October 2015 to September 2017 are studied.

\section{Material and Method}

\section{General information}

Methodology: A total of 120 URSA patients admitted to our hospital from October 2015 to September 2017 were taken as the observation subjects. They were divided into two groups based on the random number table, that is, control group $(n=60)$ and observation group $(n=60)$.

Inclusion criteria: The condition of the patient is diagnosed as URSA by laboratory, ultrasound, and other examinations; the couple has normal chromosomes; the endocrine indexes are normal; the HLA-I/II of the couple is negative; endomethal and 
cardiolipin antibodies are negative; normal liver and kidney function; no use of medicines that affect the growth and development of the fetus; no history of allergies and defects; and voluntary participation in the research and signing of informed consent.

Exclusion criteria: The condition of the patient is accompanied by coagulation function; coagulation function abnormality, uterine malformation, seminal fluid abnormality, combined severe cardiovascular and cerebrovascular diseases, autoimmune diseases such as combined thyroid disease and diabetes, and clinical data are incomplete. No significant difference was observed between the two groups in age, duration of marriage, and times of pregnancies $(\mathrm{P}>0.05)$. The data are shown in Table 1.

Table 1. Comparison of general information of patients in two groups $(\bar{x} \pm s)$.

\begin{tabular}{|c|c|c|c|c|}
\hline Group & Age (y) & Duration of marriage $(y)$ & $\begin{array}{l}\text { Times of pregnancies } \\
\text { (times) }\end{array}$ & Methodology (months) \\
\hline Observation & $31.00 \pm 4.23$ & $4.12 \pm 2.65$ & $3.20 \pm 0.61$ & $7.54 \pm 1.65$ \\
\hline Control & $30.11 \pm 5.15$ & $4.70 \pm 2.48$ & $3.08 \pm 0.62$ & $8.00 \pm 1.71$ \\
\hline $\mathrm{t}$ & 1.0344 & 1.2378 & 1.0686 & 1.4994 \\
\hline$P$ & 0.303 & 0.2182 & 0.2873 & 0.1364 \\
\hline
\end{tabular}

\section{Methodology}

Progesterone (Guangzhuo Baiyun Shan Ming Xing Pharmaceutical Co. Ltd., with SFDA approval number H44020230 and specification of $1 \mathrm{ml}: 10 \mathrm{mg}$ ) and human chorionic gonadotropin (Beijing Taige Kexin Biological Technology Co. Ltd., with SFDA approval number 3401412 for 2006) were administered to the patients in the control group, that is, $20 \mathrm{mg}$ of progesterone was injected intramuscularly once a day until the $12^{\text {th }} \mathrm{w}$ of pregnancy. Low molecular heparin (Shenzhen Saibaoer Bio-Pharmaceutical Co. Ltd., with SFDA approval number H20060191 and specification of $1 \mathrm{ml}$ : $5000 \mathrm{IU})$ was administered to the patients in the observation group based on the control group, that is, a dosage of 5000 IU was injected periumbilicus subcutaneously once a day until the $12^{\text {th }} \mathrm{w}$ of pregnancy.

\section{Observational index}

The patients in the two groups were compared statistically in terms of pregnancy outcomes, incidence of complications in pregnancy, and incidence of adverse drug reactions.

Evaluation of pregnancy outcomes: If the gestational period is more than $12 \mathrm{w}$ and the ultrasound examination shows no abnormality or delivery of live birth, then the pregnancy is determined as successful; if the embryo stops developing or spontaneous abortion occurs, then the pregnancy is determined as a failure. The complications during the pregnancy mainly include gestational hypertension, oligohydramnion, and fetal growth restriction. Adverse drug reactions mainly include gastrointestinal reactions (nausea, vomiting, and others), bleeding (ecchymosis and vaginal bleeding), and thrombocytopenia.

\section{Statistical methods}

SPSS 22.0 is adopted to perform statistical analysis on the clinical data of two groups of patients; $(\overline{\mathrm{x}} \pm \mathrm{s})$ denotes the measurement data, that is, age, duration of marriage and times of pregnancies. The t-test is conducted by using the percentage to represent enumeration data such as pregnancy success rate, incidence of pregnancy complications, and incidence of adverse drug reactions. Chi-square test is also performed. If the comparison result is $\mathrm{P}<0.05$, then a significant difference exists between the two groups.

\section{Results}

\section{Comparison of two groups in pregnancy outcomes}

For pregnancy outcomes, the pregnancy success rate of patients in the observation group is higher than that of patients in the control group at $90.00 \%$ and $68.33 \%$ respectively, which shows a significant difference $(\mathrm{P}<0.05$, Table 2$)$.

Table 2. Comparison of patients in two groups in terms of pregnancy outcomes $(n(\%))$.

\begin{tabular}{lll}
\hline Group & Successful pregnancy & Failed pregnancy \\
\hline Observation & $54(90.00)$ & $6(10.00)$ \\
\hline Control & $41(68.33)$ & $19(31.67)$ \\
\hline$X^{2}$ & 8.5389 & \\
\hline$P$ & 0.0034 & \\
\hline
\end{tabular}

\section{Comparison of two groups in incidence of pregnancy complications}

For the incidence of pregnancy complications, the results of patients in the observation group is lower than that of patients in the control group, and the data were $90.00 \%$ and $68.33 \%$, respectively, indicating a significant difference $(\mathrm{P}<0.05$, Table 3).

Table 3. Comparison of two groups in terms of pregnancy complications $(n(\%))$. 


\begin{tabular}{lllll}
\hline Group & $\begin{array}{l}\text { Gestational } \\
\text { hypertensio } \\
\mathbf{n}\end{array}$ & $\begin{array}{l}\text { Oligohydramnio } \\
\mathbf{n}\end{array}$ & $\begin{array}{l}\text { Fetal } \\
\text { growth } \\
\text { restriction }\end{array}$ & Coincidence \\
\hline Observation & $2(3.33)$ & $2(3.33)$ & $1(1.67)$ & $5(8.33)$ \\
\hline Control & $8(13.33)$ & $3(5.00)$ & $5(8.33)$ & $16(26.67)$ \\
\hline $\mathrm{X}^{2}$ & & & & 6.9841 \\
\hline $\mathrm{P}$ & & & & 0.0082 \\
\hline
\end{tabular}

\section{Comparison of two groups in incidence of adverse drug reactions}

For the incidence of adverse drug reactions, no significant difference $(\mathrm{P}>0.05)$ was observed between the patients in the observation group and those in the control group at $20.00 \%$ and $23.33 \%$, respectively (Table 4 ).

Table 4. Comparison of two groups in terms of incidence of adverse drug reactions $(n(\%))$.

\begin{tabular}{lllll}
\hline Group & $\begin{array}{l}\text { Gastrointestinal } \\
\text { reaction }\end{array}$ & Bleeding & $\begin{array}{l}\text { Thrombocytopeni } \\
\text { a }\end{array}$ & $\begin{array}{l}\text { Overall } \\
\text { incidence }\end{array}$ \\
\hline Observation & $5(8.33)$ & $4(6.67)$ & $3(5.00)$ & $12(20.00)$ \\
\hline Control & $7(11.67)$ & $4(6.67)$ & $3(5.00)$ & $14(23.33)$ \\
\hline $\mathrm{X}^{2}$ & & & & 0.1964 \\
\hline $\mathrm{P}$ & & & 0.6576 \\
\hline
\end{tabular}

\section{Discussion}

Various causes of RSA have been identified, including chromosome abnormality, immune problems, genital infection, endocrine dysfunction, anatomic abnormalities of reproductive system, and environmental factors. However, the causes of RAS for $40 \%-50 \%$ of patients remain unknown, and this condition is called URSA [6]. In recent years, a large amount of clinical studies have shown that the occurrence of URSA is related to placental vascular thrombosis. Relevant studies have shown that the serological test performed on RAS patients reveals that the plasma tissue-type plasminogen activity is significantly lower than the normal level, while the human thrombin and plasminogen activator inhibitor are significantly higher than the normal level [7]. As a result, the fibrinolytic system activity is weakened, the progress of the prethrombotic state is facilitated, or a thrombus is formed. When the thrombus is formed in the microcirculation of uterine placenta, multiple microthrombus focus may occur in the small vessels of placenta tissue or local tissue infarction may even occur [8]. Consequently, the perfusion of placental blood flow is reduced, and the blood supply for the embryo or fetus becomes insufficient, which causes a hypoxic-ischemic phenomenon. Finally, undesirable pregnancy outcomes occur. In the clinical treatment of URSA, intramuscular injections of progesterone and human chorionic gonadotropin are provided but are ineffective. In recent years, medicines such as low molecular heparin and immune globulin have been widely used in clinical practice, providing new methods for the treatment of URSA patients.

The low molecular heparin is a heparin section formed from unfractionated heparin through enzymolysis or chemical degradation. This treatment is characterized by antithrombosis, anticoagulant, and anti-inflammatory effects, and it helps protect the vascular endothelial cell, regulate cell proliferation, reduce blood viscosity, enhance the microcirculation of uterine placenta, and improve the perfusion of placental blood flow [9]. As a result, this treatment promotes embryonic and fetal growth and development, and enhances pregnancy outcomes. Clinical research shows that the mechanism of action for low molecular heparin may be the following [10]: (1) It promotes thrombolysis and stimulates the endothelial cells to release the endogenous heparin substance to achieve the antithrombus effect and improve the concentration of plasma plasminogen activator. (2) The molecular weight is relatively small and is not neutralized by the platelet factor; thus, low molecular heparin induces the endothelial cells to release the prostacyclin-like substance and increase the plasminogen activator to dissolve the thrombolysis. (3) Low molecular heparin activates angiotensin and vasoactive substances, increases blood perfusion, and inhibit vasoconstriction and reduce effusion to further relieve the edema.

The results of this study have shown that as regards pregnancy outcomes, the pregnancy success rate of patients in the observation group is significantly higher than that of patients in the control group $(\mathrm{P}<0.05)$; in the incidence of pregnancy complications, the result for patients in the observation group are significantly lower than that of the patients in the control group $(\mathrm{P}<0.05)$; and in the incidence of adverse drug reactions, the comparison between patients in the two groups do not show any significant difference $(\mathrm{P}>0.05)$. The results are basically identical with those reported in the literature, which means that the efficacy of low molecular heparin in treating URSA is specific. Characterized by anti-thrombosis and anticoagulant effects, low molecular heparin protects the vascular endothelial cell, reduces blood viscosity, improves microcirculation of uterine placenta, enhances the perfusion of placental blood flow, and facilitates embryonic and fetal growth and development.

\section{Conclusion}

The low molecular heparin administered to the URSA patients manifests a strong clinical effect because it not only improves the pregnancy success rate but also reduces the incidence of complications. This treatment is safe and reliable, and is suitable for application in clinical studies.

\section{Acknowledgments}

This work was supported by grants from the National Natural Science Foundation of China (81673735). 


\section{References}

1. Banadakoppa M, Chauhan MS, Havemann D, Balakrishnan M, Dominic JS, Yallampalli C. Spontaneous abortion is associated with elevated systemic C5a and reduced mRNA of complement inhibitory proteins in placenta. Clin Exp Immunol 2014; 177: 743-749.

2. Mahdi TN, Gholamhassan V, Hossein AE, Vida H. Acute and chronic effects of opiates and dopamine on yawning, penile erection and genital grooming behaviors in male Wistar rats. Biomed Res India 2017; 28: 6931-6936.

3. Ajayi OO, Charles-Davies MA, Arinola OG. Progesterone, selected heavy metals and micronutrients in pregnant Nigerian women with a history of recurrent spontaneous abortion. Afr Health Sci 2012; 12: 153-159.

4. Hafiz TA, Mubaraki MA. The potential role of Ziziphus spina-christi leaf extracts against Plasmodium bergheiinduced liver and spleen injury. Biomed Res India 2016; 27: 1027-1032.

5. Abdoli A, Dalimi A, Soltanghoraee H, Ghaffarifar F. Molecular detection and genotypic characterization of toxoplasma gondii in paraffin-embedded fetoplacental tissues of women with recurrent spontaneous abortion. Int J Fertil Steril 2017; 10: 327-336.

6. Zhang HN, Li YH, Huang XZ, Li J, Luo YH. Preparation of silkworm pupa peptides and its antihypertensive activity in spontaneously hypertensive rats. Lat Am J Pharm 2012; 31: $1155-1160$.
7. Chung Y, Kim H, Im E, Kim P, Yang H. Th 17 cells and nesfatin-1 are associated with spontaneous abortion in the $\mathrm{CBA} / \mathrm{j} \times \mathrm{DBA} / 2$ mouse model. Dev Reprod 2015; 19: 243-252.

8. Andersen SL, Olsen J, Wu CS, Laurberg P. Spontaneous abortion, stillbirth and hyperthyroidism: a Danish population-based study. Eur Thyroid J 2014; 3: 164-172.

9. Darwish IA, Askal HF, Refaat IH, Marzouq MA, Ahamad SR. Novel microwell-based spectrophotometric method with high throughput for determination of 4-quinolone antibiotics in their pharmaceutical formulations via spontaneous formation of water soluble ion-pair complexes. Lat Am J Pharm 2013; 32: 1273-1279.

10. Smythe MA, Priziola J, Dobesh PP, Wirth D, Cuker A, Wittkowsky AK. Guidance for the practical management of the heparin anticoagulants in the treatment of venous thromboembolism. J Thromb Thrombolysis 2016; 41: 165-186.

\section{*Correspondence to}

Ai-Wu Wei

The Assisted Reproductive Center

The First Affiliated Hospital of Henan University of Traditional Chinese Medicine

PR China 